10 years ESJ

Special edition

\title{
Fostering Meaningful and Creative Connections in Higher Education: Contributions from Music Education
}

\author{
Milhano Sandrina, PhD \\ Polytechnic Institute of Leiria, CI \& DEI, \\ High School of Education and Social Sciences, Portugal
}

Doi: 10.19044/esj.2021.v17n26p27

Submitted: 20 March 2021

Accepted: 18 June 2021

Published: 09 August 2021
Copyright 2021 Author(s)

Under Creative Commons BY-NC-ND

4.0 OPEN ACCESS

Cite As:

Sandrina M. (2021). Fostering Meaningful and Creative Connections in Higher Education: Contributions from Music Education. European Scientific Journal, ESJ, 17 (26), 27. https://doi.org/10.19044/esj.2021.v17n26p27

\begin{abstract}
This paper focuses on contributing to the reflection on the importance of providing opportunities to foster meaningful and creative connections in higher education. In a context of growing plurality, heterogeneity and diversity of backgrounds, languages, cultures, identities, roles, and purpose influences the sociocultural relations and professional interactions that occur and are formed within higher education communities of knowledge and learning, which are explored from the perspective of music education. A narrative approach on participant's views about their participation in an elective music program was developed inside the framework of informal education. Issues that were discussed the most across the datasets by participants individual accounts are expressed through themes that fall into three broad areas: previous musical experiences, significant influences for music participation, and perceptions of the participation in the music program. Results suggest that the informal music program provided participants with a context for a safe emotional, social, cultural, and musical experience, and thus heterogeneity and diversity are seen as enriching factors. Some considerations are made on the ways through which music can help to foster connections and sense of humanity in higher education. This provides some insights into the relevance of fostering musical participation as part of the cultural responsibility of higher education institutions for participants.
\end{abstract}


Keywords: Connections, higher education, informal music practice, music education, music learning

\section{Introduction}

For many higher education institution (HEI), heterogeneity and diversity are topical issues, alongside the populations they include and interact from. These themes are complex as they relate not only with the diversity of forms of knowledge, learning and teaching present in HEI, but also with multicultural and social factors such as the globalization and migratory flows (Varghese, 2013), as well as strategic management and internationalization approaches. The phenomena of globalization and the way it is increasing worldwide fosters an interconnectedness that combines economic, cultural, and social changes, which has reciprocal impacts on higher education (OECD, 2009).

Along with these ongoing processes, new related challenges continuously emerge in HEI. This finds expression, among other issues, within the ethical development of the organizational processes and the social dimension of HEI responsibility (ORSIES, 2018), which is geared towards more inclusive and connected higher education (European Commission, nd.). Besides the invaluable contribution of HEI to the society, including fulfilling its social responsibility in several dimensions, higher education communities are seeking for more inclusive opportunities to creatively and meaningfully connect and to contribute a sense of common understanding.

The confluence of the pluralities, heterogeneities, diversities, and needs earlier mentioned was examined at Leiria School of Education and Social Sciences in Portugal. In this new scenario where higher education has been immersed, the challenge to perceive cultural diversity as a factor of mutual enrichment, in addition to a more global and systematical approach to the cultural relevance of HEI mission towards its communities, constitutes a variable of academic excellence with an important contribution for a more inclusive and connected higher education and society.

Therefore, this paper addresses the relevance of providing opportunities to foster meaningful and creative connections in higher education. A narrative approach on participant's views about their participation in an elective music program was developed inside the framework of informal education. Some considerations are also made from the perspective of music education on the ways through which music can help foster those connections and sense of humanity in higher education. 


\subsection{Fostering the Cultural Dimension Responsibility of Higher Education Institutions}

Each year, new students join the Portuguese community of higher education with hopes for a meaningful and enriching experience. Some students are local, but most of them come from different regions of the country, with many aspirations according to the experiences they anticipated. In the context-specific of the School of Education and Social Sciences in Leiria, a growing percentage of students come from general and specific cooperation agreements programs, which exist with institutions from Portuguese speaking countries such as South-America and Asia. This reality is consentaneous with the approach presented by OECD (2019) in the Review of Higher Education and Research and Innovation. This presents Portugal as a country with a comparatively small size and a tradition of openness and dependency on international trade. As a result, the expansion of higher education has led to an increasing diversification of students' profile.

Those 'local' and 'abroad' students find, in this littoral city of the center of Portugal, a place to interact with the international students. This also includes the ones that come based on the mobility experiences provided by Erasmus Program. Student's populations emanate from different places, with different linguistic and cultural references, background, and expectations. Many also have hopes for a social and cultural 'immersion' experience. However, many students find it difficult, and sometimes impossible, to make meaningful contact during their university life, especially with locals. According to research, some consider the 'lack of it as a personal failure' (Meier \& Daniels, 2013).

Thus, higher education institutions (HEI) are communities which comprises of diverse students' populations along with teachers, academic staff, and researchers. Each one of these groups is characterized by their own specificities and diversities. This 'subcommunities' are embodied with local, regional, national, and international social networks that interact and influence each other in a living academic system. Most of these groups wish to make meaningful contact between themselves and among each other. However, many times, they experience some constrains. One of the constrains in this paper and also recognized by research is the lack of opportunities and contexts to meaningfully connect these subcommunities.

HEI are characterized by a growing plurality, heterogeneity and diversity of backgrounds, languages, cultures, identities, experiences, roles, and purposes that influence the sociocultural relations and professional interactions that occur and are formed in those communities of knowledge and learning. As mentioned by UNESCO (2009), HEI reflect societies in its cultural heterogeneity, influences, interactions, and exchanges, which implies a diversity of forms of knowledge and sources of production. 
In a situation whereby cultural policies are developed from global, national, regional, and local dimensions based on the current dynamics of change, HEI cultural responsibilities therefore takes on a singular importance and need to assume greater relevance in this organizations and is formally addressed.

One of the underlying ideas is the promotion of cultural citizenship, which connects with the educational and social responsibilities (ORSIES, 2018) of HEI and its recognized impacts.

Evidence based research on the way arts and humanity deals with major global current issues such as migrations and cultural diversity, among others, have been illustrated recently in different international forums such as The World Humanities Conference (http://www.humanities2017.org/en), held in 2017, and the 2019 OECD/International Council of Museums document titled "Culture and Local Development: Maximising the impact". Through a holistic approach, these forums emphasized the transforming power of culture in all its components. Culture is seen as a system of beliefs, values, customs, behaviors, and artifacts shared by members of a given society, which contributes for cohesion, unity, integration of migrants, political participation, mutual understanding, and creativity (Candeias \& Lopes, 2019).

\subsection{The Role of Music and Music Education in Fostering Meaningful and Creative Connections}

Over the last decades, the literature review on how music can contribute to address these complexities is vast. Also, many distinctive approaches have been presented from the musical sciences, which have significant impacts on the field of music education. The human nature of music (Malloch \& Trevarthen, 2018) has been profoundly investigated. Music is seen as inherently ambiguous and as one of the "most universal ways of expression and communication in human life. It is also present in the everyday lives of people of all ages and from all cultures around the world" (Biasutti, Welch, MacRitchie, McPherson \& Himonides, 2020, p.2). Music can transform and shape our minds (Machover, 2004) and may be among the most personal and meaningful of all the activities humans possess (Folkestad, 2002).

Multidisciplinary studies have explained how music can be seen as a fundamental channel of communication. Also, the biological, cognitive, social, and cultural processes which underlie such communication provide a "means by which people can share emotions, intentions, and meanings even though their spoken languages may be mutually incomprehensible" (Hargreaves, MacDonald \& Miell, 2005, p.1). Music can be used increasingly as a means by which people formulate and express individual identities (MacDonald, Hargreaves \& Miell, 2002, 2017). Music can also represent a great socio-educational significance in the life of each person, which 
reinforces numerous personal, social, affective, emotional, and relational skills (Milhano, 2014; Margarido, Santos, Margarido, Milhano \& Póvoa, 2020). As a performative art form, it is "inherently social" and "inherently creative" (Bishop, 2018).

This paper shares the assumption that music education goes beyond the music class (Hargreaves, Marshall, \& North, 2003) and embraces a broad range of activities in different non-formal and informal contexts (Milhano, $2012 \mathrm{~b}$ ). Thus, this is a wake-up call to music educators to transfer democratic issues into practice by using the arts "to involve local communities in sustainable reciprocal partnerships" (Richardson, 2007, p.205). According to Boal-Palheiros and Boia (2020, p.199), as the world changes, music education must be "concerned with changing itself".

Some of the important conceptual developments that the field of music education has witnessed are concerned with the idea of "increasingly and importantly becoming part of global thinking on cultural diversity" (Schippers, 2010, p.40). Research in educational contexts have discussed how music education can be used as an effective platform to open the doors to multiculturalism and cultural understanding (Dawn \& Southcott, 2009), thereby promoting intercultural dialogue (Côrte-Real, 2011) and forging "new responses from music educators to the conditions of globalization" (Hebert \& Karlsen, 2010, p.10). It has also focused on how "the seminal role of music and music education, in reflecting and supporting culture, can be a potent force educationally" (Walker, 2000).

In HEI, different settings of music learning usually coexist. These contrasting settings and contexts of learning and social interaction through music have their own sets of underlying values, epistemologies, and insights into eventual ways of re-invigorating the musical involvement of the population (Green, 2002, 2008). In the context of cultural responsibility of HEI, it is important to consider the provision of institutional music programs which are focused on the potential and promise that music learning [and practice] holds to enrich the lives of its participants and audience (Veblen, 2018, p.252).

Although the understanding of 'context' has been recognized as important amongst educational research, it is imperative to acknowledge the complex myriad of ongoing factors, forces, actors, institutions, objects, and phenomena surrounding the different settings of music learning, that coexist both outside and inside institutions lives, which interact and impact each other. As highlighted by Bronfenbrenner (1995, 2005), macro-level systems such as social and cultural values, economic conditions, material resources, and opportunity structures exert significant influence on micro-level social and cultural systems such as the school and, in this case, HEI. 
This demonstrates the complex myriad of ongoing influences and the specificity of various contexts that may be learnt and manifested musically (Veblen, 2018) in different ways and selves in adult music learning and participation (Creech, Varvarigou \& Hallam, 2020).

The music program in focus was developed for successful participatory music making (Turino, 2008).

In this community of musical practice, the repertoire is negotiated between participants with stylistic flexibility. The pedagogical practice is guided by a professional popular musician (Milhano, 2020). It also reflects learning and teaching within popular music (Green, 2002, 2008), alongside shared teaching. Practices of transmission are mostly associated with the repertoire of the styles and are usually dependent on repetition, listening to a recording or one of the participants. This is done within an informal approach before referring to a score. The approach to public performance is informal (Milhano, Sousa \& Lopes, 2019), which is in line with the embodied set of performance practices of the musical styles performed (rock, pop, jazz, ...).

\section{Methods of Data Collection and Analysis}

The objective of this study was to obtain the participant's views about their participation in an elective music program called "ESECS Orquestra", which was offered at the School of Education and Social Sciences in Leiria, Portugal. The context-specific addressed in this exploratory study is an elective music program, which was developed inside the framework of informal education. This refers to the concept of the community of musical practice (Kenny, 2016).

The core of twelve participants in the music program remained relatively stable during the academic year, with participants bringing contributions from their different musical, linguistic, geographical, and cultural experiences to the program. This cultural diversity can be seen in terms of the scope of their ages (between 18 and 65 years), their educational and musical backgrounds, their roles in the higher education institution, and their geographic origin (Portugal, Brazil, Ecuador, China, Italy and Germany). the approach in

Scottish traditional music (Cope, 2005) and in popular music (L. Green, 2008) has

been one of informal, shared teaching

the approach in

Scottish traditional music (Cope, 2005) and in popular music (L. Green, 2008) has

been one of informal, shared teaching

the approach in 
Scottish traditional music (Cope, 2005) and in popular music (L. Green, 2008) has

been one of informal, shared teaching

A narrative approach was used to conduct this research (Bold, 2012), which aligns with the purpose of the research. This enables the development of a critical and reflective approach to music practice and involvement. Furthermore, it provides a better understanding of the subjective world of participants experience in the music program and their interpretations of it (Cohen, Manion \& Morrison, 2007, p.23), as well as the meaningful concrete relations which are implicit in the context of a particular situation (Moustakas, 1994). Furthermore, it supports the data examination and analysis, which provides a better understanding of participant's views about their participation in the music program. It also offers some insights into the relevance of incorporating opportunities to musical participation as part of the cultural responsibility in higher education institutions.

Within this study, the researcher is seen as "participant-as-observer" (Cohen, Manion \& Morrison, 2007, p.311), engaging in the musical activities observed and playing "a direct and intimate role" within qualitative research (Corbin-Dwyer \& Buckle, 2009, p.2).

Individual accounts were collected through a survey. This made it possible to obtain information directly from the people involved in the community of musical practice. The survey was developed in both Portuguese and English in order to facilitate the comprehension of non-native Portuguese speaking language participants. The data collection instrument was designed and adapted from an already published one by Pitts (2009). This made it possible to collect retrospective accounts of formative musical influences and opportunities from adults who had sustained an active interest in music throughout their lives. The adapted survey was validated by a group of three experts (in music education and foreign language). This helped to eliminate possible existing dificulties in regards to the comprehension of the texts and its meaning.

Written responses were used which provided brief details of their age, nationality, genre, role in academia, language, musical background, as well as responses to some stimulus questions. Participants were recruited directly in the music program, with results drew on participants informed consentient. Responses were received in June 2019 from six participants, representing 50\% of the group. Responding participants were aged between 18 and 30 years, and they were from 4 different nationalities: Portuguese, Chinese, Italian, and German. Each participant was given an anonymous code, using a letter.

Issues that were discussed the most across the datasets by participants were considered to be the most significant (Braun \& Clarke, 2006). Those issues were organized within categories, analyzed and interpreted, and was 
expressed through themes using accounts coded in more detail to illustrate respondents' views.

\section{Findings and Discussion}

Results are expressed through themes which fall into three broad areas: previous musical experiences, significant influences for music participation, and perceptions of the participation in the music program.

\section{Previous Musical Experiences}

Irrespective of the context, all participants in the music program mentioned that they had previous musical experiences within music practice, through singing or playing an instrument. They had many of these experiences during their childhood and adolescence, which was expressed, mostly, as positive musical experiences.

"I began having music education at kindergarten, aged three years old (...) After, I also continued having music education, usually connect to beat, music with beat and rhythm (...) I think that these experiences influenced me a lot since today, I feel a strong intuitive sense (...) I can, through intuition, improvise some music's". (Participant B, abroad student who sings and plays piano in the music program)

Participant C, also an abroad student aged 21, who usually sings and plays the bass guitar, the piano and the flute, explains: "we usually sung at school, every morning" (...) "I had choral, piano and classic guitar classes". Other participants, namely Portuguese, mentioned music education classes at school as a curricular subject and the participation in school festivities:

"I only had music at school in the 5th and 6th grades. We just played recorder. On the last day of classes, the teacher said that we had two minutes to try the musical instrument we wanted. I chose to try the drums. I liked the recorder very much." (Participant F, researcher, Portuguese)

Participant A, a Portuguese student, recalls how participation in the school festivities and extracurricular music classes in a music school were important in developing her strong connection with music: "I remember the concert made by the 5th and 6th grade school guitar club. But, the best of all, was having joined the music academy - it was really where I had a great relationship with music".

These experiences for the participants, both of music learning and practice, took place as a curricular subject at school, as extracurricular activities outside school, and through local community musical ensembles and initiatives. For Portuguese participants, the importance of local, social, and 
cultural influences which provides them with opportunities to participate in elective, voluntary, and self-selected musical activities outside school have been highlighted in line with previous research (Milhano, 2011, 2012b)). The performative and social nature of this music participation (Bishop, 2018) and the role they play as motivational opportunities (Hargreaves, 1996) are emphasized in participants discourses. This has a significant impact on learning and on the relationships that they developed in those musical communities, which contributes to sense of belonging, identity, and meaningmaking (Heuser, 2017).

The analysis and interpretation of the data collected through the survey suggests the existence of some apparent difference between Portuguese and abroad participants regarding their previous contexts of musical participation. Portuguese participants included less references of their involvement in music at school. This is because the major emphasis was on the experiences that happened mainly outside school, in informal contexts or as an extracurricular music activity developed in community contexts (Milhano, 2012a; Milhano, Sousa \& Lopes, 2019). This issue was mentioned during some of the musical interactions that happened between the researcher and participants. Oral evidence was also gathered which aligned with the written responses collected through the survey. Thus, this issue may need further research since it revealed the opportunities available for young people to gain access to musical experiences at school.

These results also illustrate, to some extent, participants inherent musical diversity which are provided through their musical backgrounds, profiles, languages, cultures, experiences, music knowledge, and practices. These contrasting results found among Portuguese and abroad participants may be understood in light of this diversity while considering comparative and historical research on music education. In this context, it is important to take into consideration that Portugal presented a shorter cycle of artistic education. According to Graça Mota (2014), it is a "full story of contradictions", which could possibly be a limitation factor for the musical opportunities provided for Portuguese participants, with some impacts on their perceptions.

Participants further emphasized the different impacts of their previous musical experiences on their lifelong musical interest (Pitts, 2009), on their opportunities and motivations in music (Hargreaves, 1996; Milhano, 2020), and on how the perceived quality of the musical interactions, situation, and learning experiences are seen as important factors on how they use music and value it.

\section{Significant Influences for Music Participation}

The emphasis on family, especially on parents, in providing participants with stimulus and opportunities to music learning or involvement 
was, in most cases, directly mentioned. This idea is very evident in the accounts of participant D, who is a Portuguese student that sings and plays the guitar in the music program: "My parents [influenced my musical behavior], because, besides not having any connection with music, they always supported me to learn a musical instrument or to go to a choir".

Participants clearly mentioned their parents as the persons that were more supportive of their musical participation and the existence of familiars with music professions (participant F). Participants also acknowledged the influences of friends in their musical choices.

Some participants, such as participant A, B and E, also mentioned their music teachers' positive influences on their musical involvement, referring to extracurricular instrumental or voice classes held outside school. As Jorgensen (2008) explained, the relationships and interactions between teacher and student and their commitment to particular beliefs and practices are relevant and affected by expectations and instructional contexts. The notion that pupil's developing musical identities can be shaped by socio-cultural factors (Hargreaves, 1996; MacDonald, Hargreaves \& Miell, 2002, 2017) is present in the rationalization of participants development, perception, and motivation in music.

According to Milhano (2012a), self-perceptions and motivations in music may be intimately associated with the specific contexts of music education experienced. This influences their own opinions and selfperceptions. However, this influence also comes from their parents, friends or music teachers. It is possible to suggest, according to participants accounts, that they have revealed mainly positive musical experiences. Those experiences were associated with the role of music in their lives during childhood and adolescence and with influencing persons of their familiar, social, and cultural environment.

Therefore, significant influences for participants, in regards to music participation, includes the combination of parental encouragement and home resources with informal influences from cultural participation and involvement opportunities presented in the community. This demonstrates the complex myriad of ongoing influences and the specificity of various contexts that may be learnt and manifested musically (Veblen, 2018) in different ways and selves in adult music learning and participation (Creech, et. al, 2020).

\section{The Value of Music in the Context of the Program}

Participant's narratives provided insights on the ways they value and use music in the context of the music program and how it contributed to fulfill their needs and interests.

The music program enabled them to obtain more musical knowledge. Therefore, this provided them with relevant cultural and artistic experiences: 
"It is an opportunity to develop our musical aptitude inside the academic environment and to socialize with persons that are not exclusively from our academic program" (Participant E). "It enables me to acquire more music knowledge" (Participant C).

Participant $\mathrm{F}$ contributed to this view by adding an emotional and relational reference to the learning environment: "I love the atmosphere and I feel that I developed a lot musically" (Participant F). This view may be connected to the notion of Heuser (2017) who stated that the collective knowledge, which is shared, learned, and produced in this community of musical practice through weekly common experiences, contributed in fostering their sense of belonging, identity, and meaning-making in music.

The music program was seen as an opportunity to learn, to make friends, and to make music. Positive attitudes were identified, which was related to the way they felt that their own musical resources and knowledge were valued and expressed through 'informal' aspects of music practice such as repertoire choice (Sloboda \& Davidson's, 1996).

Participants seem to also share a common understanding of ways of music engagement, a sense of membership in the music program, being comfortable with their roles, identities and learning value, which are shared through collective musical endeavor. The music program is:

"like a family and makes music be present all weeks". This idea is supported by participant B: "(...) it is a great opportunity to make music and find friends. It's a very familiar environment and professional, at the same time" (Participant A).

Also, participants had the opportunity to perform inside the HEI for the academic population. Some of these performances included the participation of invited popular local musicians and musical groups in an informal participatory culture of music practice (Waldron, Mantie, Partti \& Tobias, 2017). They also had the opportunity to perform outside the HEI through invitation to local popular music concert houses. This led to a musical and social interaction among themselves through virtual media, thereby sustaining the existing musical community (Mitchell, 2015) and facilitating the communication between the group. The bidirectional involvement of the higher educational institution and communities (Milhano, Reis \& Mangas, 2020) provided participants with a variety of experiences in the field of local and regional educational and musical practices, which enriched participants inclusion in local contexts of socialization.

The importance of the music program in creating opportunities, both for lifelong music involvement and interest (Pitts, 2009) and for fostering links of sociability through this social 'immersion' experience, is stated by participants. Both 'local' and 'abroad' participants provided evidence on the 
way the music program contributed to reinforce numerous personal, social, affective, emotional, and relational skills among them (Milhano, 2014; Margarido, et. al, 2020). This led to a sense of belonging in the 'music community' (Kenny, 2016), as well as in the local community.

"I am away from home and away from all the musical projects in which I participated in my land. ESECS Orquestra is the only contact that I have with music in Leiria. Furthermore, the ambience with the other participants is amazing, I have created many friendships and spent here great moments". (Participant C)

Furthermore, findings also suggest that a narrative approach on participant's views about their participation in an elective music program (ESECS Orquestra) was developed inside the framework of informal education. This provided them with a context for a safe emotional, social, cultural, and musical experience. Participants accounts emphasized how the music program contributed to reinforce the links of sociability within and outside academia. This provided a context where heterogeneity and diversity are seen as enriching factors.

\section{Conclusion}

This paper addressed participant's views about their participation in an elective music program, which was developed inside the framework of informal education in a higher education institution.

Using a narrative approach, individual accounts were collected through a survey. This made it possible to obtain information directly from the people involved in the community of musical practice. Results suggested that the program provided participants with a context for a safe emotional, social, cultural, and musical experience, and thus heterogeneity and diversity were seen as enriching factors. The participants musical backgrounds, languages, cultures, identities, roles, and purposes are influential factors that enables the development of a more critically and reflective approach to the musical practice of the community. Also, it offered some insights into the relevance of providing opportunities to informal music practices in higher education, as part of their cultural responsibility for the participants.

Music education research contributed to this framework by stressing on how the quality of the musical interactions, situations, and learning experiences are important factors on the way music is used and valued. It also reflected the ways informal music programs can help to enhance opportunities for more inclusive contexts, thereby fostering connections and sense of common understanding in academic institutions. 


\section{Aknowlegment}

This work is funded by National Funds through the FCT - Foundation for Science and Technology, I.P., within the scope of the project Ref ${ }^{a}$ UIDB/05507/2020. Furthermore, we would like to thank the Centre for Studies in Education and Innovation (CI\&DEI) and the Polytechnic of Leiria for their support.

\section{References:}

1. Biasutti, M., Welch, G. F., MacRitchie, J., McPherson, G. E., \& Himonides, E. (Eds.). (2020). The Impact of Music on Human Development and Well-Being. Lausanne: Frontiers Media SA. https://doi: 10.3389/978-2-88963-683-9.

2. Bishop, L. (2018). Collaborative Musical Creativity: How Ensembles Coordinate Spontaneity. Front. Psychol, 9:1285. https://doi: 10.3389/fpsyg.2018.01285

3. Braun, V. \& Clarke, V. (2006). Using thematic analysis in psychology. Qualitative Research in Psychology, 3(2), 77-101. https://doi.org/10.1191/1478088706qp063oa

4. Boal-Palheiros, G. \& Boia, P. S. (2020). Formação de professores de música e práticas de educação musical nas escolas. In Boal-Palheiros, G. \& Boia, P. S. (Org.), Desafios em Educação Musical, Porto: CIPEM/INET-md /Escola Superior de Educação do Politécnico do Porto.

5. Bold, C. (2012). Using Narrative in Research. Sage.

6. Bronfenbrenner, U. (1995). Developmental ecology through space and time: A future perspective. In Examining lives in context: Perspectives on the ecology of human development. American Psychological Association. 619-647.

7. Bronfenbrenner, U. (2005). Making human beings human: Bioecological perspectives on human development. Sage.

8. Candeias, A. \& Lopes, M.C. (Coord.). (2019). Agenda temática de I\&I Cultura e Património Cultural. FCT.

9. Cohen, L., Manion, L., \& Morrison, K. (2007). Research Methods in

10. Education. 6th Ed. London: Routledge Falmer.

11. Corbin-Dwyer, S. \& Buckle, J. (2009). The space between: On being an insideroutsider in qualitative research. International Journal of Qualitative Methods, 8 (1), 54-63.

12. Côrte-Real, M. S. J. (2011). Music and intercultural dialogue rehearsing life performance at school. Intercultural Education, 22:4, 317-325. https://doi:10.1080/14675986.2011.617424

13. Creech, A., Varvarigou, M., \& Hallam S. (2020). Lifelong Musical Possible Selves: Adult Music Learning and Participation. In: Contexts 
for Music Learning and Participation. Palgrave Macmillan, Cham. https://doi.org/10.1007/978-3-030-48262-6_7

14. Dawn, J. \& Southcott, J. (2009). Opening the doors to multiculturalism: Australian preservice music teacher education students' understandings of cultural diversity. Music Education Research, 11:4, 457-472.

15. European Commission. (n.d.). Inclusive and connected higher education $\mid$ Education and Training. https://ec.europa.eu/education/policies/higher-education/inclusiveand-connected-higher-education_en

16. Folkestad, G. (2002). National identity and music. In R. R. MacDonald (Ed.), Musical identities, Oxford University Press.

17. Green, L. (2002). How popular musicians learn. A Way Ahead for Music Education. London: Ashgate.

18. Green, L. (2008). Music, informal learning and the school: a new classroom pedagogy. London: Ashgate.

19. Hargreaves, D. J. (1996). The developmental Psychology of Music. Cambridge. Cambridge University Press.

20. Hargreaves, D. J., MacDonald, R., \& Miell, D. (2005). How do people communicate using music. Musical communication, 1, 1-26.

21. Hargreaves, D. J., Marshall, N., \& North, A. (2003). Music education in the twenty-first century: a psychological perspective. British Journal of Music Education, 20(02). https://doi.org/10.1017/S0265051703005357

22. Hebert, D. \& Karlsen, S. (2010). Editorial introduction: Multiculturalism and music education. Musiikkikasvatus The Finnish Journal of Music Education (FJME), 13(1).

23. Heuser, F. (2017). Review of Communities of Musical Practice, by Ailbhe Kenny. Philosophy of Music Education Review, 25 (2), 214220.

24. Jorgensen, E. R. (2008). The Art of Teaching Music, Transforming Music Education. Indiana University Press, pp. 21-61.

25. Kenny, A. (2016). Communities of musical practice. Routledge.

26. MacDonald, R., Hargreaves, D. J., \& Miell, D. (2002). Musical Identities. Oxford University Press.

27. MacDonald, R., Hargreaves, D. J., \& Miell, D. (2017). Handbook of Musical Identities. Oxford University Press.

28. Machover, T. (2004). Shaping minds musically. BT Technology Journal, 22 (4).

29. Malloch, S. \& Trevarthen, C. (2018). The Human Nature of Music. Frontiers in psychology, 9, 1680. https://doi.org/10.3389/fpsyg.2018.01680 
30. Margarido, C., Santos, R., Margarido, E., Milhano, S., \& Póvoa, V. (2020). Opera in Prison: Impact of an artistic project on the reintegration of young people in prison. In Eighth International Conference on Technological Ecosystems for Enhancing Multiculturality (TEEM'20). Association for Computing Machinery, New York, NY, USA, 827-832. https://doi.org/10.1145/3434780.3436593

31. Milhano, S. (2011). Reshaping identities musically: a cross-sequential research with children. In Ascott, R. \& Girão, L. M. (Eds.), Presence in the Mindfield: Art, Identity and the Technology of Transformation. Universidade de Aveiro, 181-186.

32. Milhano, S. (2012a). Primary school children's' opportunities and motivations in music: a research in different contexts of music education, EDULEARN12 International Association for Technology, Educationand Development, 6591-6600.

33. Milhano, S. (2012b). Music teachers and their pupils: musical activities, self-perceptions, and attitudes to music. EDULEARN12 International Association for Technology, Educationand Development.

34. (2014). Práticas musicais e artísticas e a (re)construção de identidades numa comunidade sénior, In Fontes, A., Sousa, J., Lopes, M.S. P., Mónico, S. (Org.). Cultura e Participação: Animação Sociocultural em contextos Iberoamericanos, Leiria, Rede Iberoamericana de Animação Sociocultural, 223-233.

35. Milhano, S., Sousa, J., \& Lopes, S. (2019). Primary Pupil's Perceptions of their Participation in a Performative Music Project Crianças ao Palco. The Future of Education Conference Proceedings 2019, Firenze, Pixel, 215-234. https://doi.org/10.26352/D627_23849509_2019

36. Milhano, S. (2020). Exploring Formative Routes, Opportunities, and Events in Music Education. The Future of Education Conference Proceedings 2020, Firenze, Pixel, 4594- 4619. https://doi.org/10.26352/E618_2384-9509

37. Milhano, S., Reis, S., \& Mangas, C. (2020). Local and regional dynamics of cooperation to promote success in school - an integrated and innovative project network. EDULEARN20 Proceedings, Valência, IATED, 1804-1813.

https://doi.org/10.21125/edulearn.2020.0587

38. Mitchell, R. (2015). The development of social relations during residence abroad. Innovation in Language Learning and Teaching, 9:1, 22-33. https://doi.org/10.1080/17501229.2014.995762 
39. Meier, G. \& Daniels, H. (2013). 'Just not being able to make friends': social interaction during the year abroad in modern foreign language degrees. Research Papers in Education, 28:2, 212-238. https://doi.org/10.1080/02671522.2011.629734

40. Mota, G. (2014). Educação Musical em Portugal: Uma história plena de contradições. Debates - Cadernos do Programa de Pós-Graduação em Música, Centro de Letras e Artes 13, 41-50.

41. Moustakas, C. (1994). Phenomenological research methods. SAGE Publications, Inc. https://www.doi.org/10.4135/9781412995658

42. OECD (2009). Globalisation and higher education: what might the future bring?. IMHE-Info December, OECD, Paris.

43. OECD (2019). OECD Review of Higher Education, Research and Innovation: Portugal. OECD Publishing, Paris.

44. OECD, International Council of Museums (2019). Culture and Local Development: Maximising the impact. A guide for local governments, communities and museums. https://doi.org/10.1787/9a855be5-en

45. ORSIES (2018). Livro Verde sobre Responsabilidade Social e Instituições de Ensino Superior. PRESS FORUM, SA - Comunicação Social.

46. Pitts, S. E. (2009). Roots and routes in adult musical participation: investigating the impact of home and school on lifelong musical interest and involvement. British Journal of Music Education, 26(3), 241-256.

47. Richardson, C. P. (2007) Engaging the world: music education and the big ideas. Music Education Research, 9:2, 205-214. https://doi.org/10.1080/14613800701384318

48. Schippers, H. (2010). Facing the music: Three personal experiences, five historical snapshots, seven conceptual shifts and twelve continua as an accessible pathway to understand different approaches to cultural diversity in music education. Musiikkikasvatus The Finnish Journal of Music Education (FJME), 13 (1), 39-44.

49. Sloboda, J. \& Davidson, J. (1996). The young performing musician. In Deliège, I. \& Sloboda, J. (Eds.), Musical Beginnings. Oxford University Press.

50. The World Humanities Conference (2017). http://www.humanities2017.org/en

51. Turino, T. (2008). Music as social life: The politics of participation. Chicago: The University of Chicago Press.

52. UNESCO (2009). Investing in Cultural Diversity and Intercultural Dialogue - World report. UNESCO. 
53. Varghese, N. V. (2013). Globalization and higher education: Changing trends in cross border education. Analytical reports in international education, 5(1), 7-20.

54. Veblen, K. K. (2018). Adult music learning in formal, nonformal, and informal contexts. Special needs, community music, and adult learning: An Oxford handbook of music education, 4, 243-256.

55. Waldron, J., Mantie, R., Partti, H., \& Tobias, E. S. (2017). A brave new world: theory to practice in participatory culture and music learning and teaching, Music Education Research. https://doi.org/10.1080/14613808.2017.1339027

56. Walker, R. (2000). Multiculturalism and Music Re-Attached to Music Education. Philosophy of Music Education Review, 8(1), 31-39. 